\title{
Treatment of Displaced Mid-Clavicle Fractures by Closed Titanium Elastic Nail
}

\author{
Hrushikesh Saraf1, Sarang Kasture ${ }^{2 *}$ \\ ${ }^{1}$ Shashwat Multispeciality Hospital, Pune, India \\ ${ }^{2}$ MIMER Medical College, Pune, India \\ Email: *sarangkasture@gmail.com
}

Received 11 January 2016; accepted 11 February 2016; published 14 February 2016

Copyright (C) 2016 by authors and Scientific Research Publishing Inc.

This work is licensed under the Creative Commons Attribution International License (CC BY). http://creativecommons.org/licenses/by/4.0/

(c) (i) Open Access

\begin{abstract}
Introduction: Recently, intramedullary nailing for displaced middle third fractures of clavicle has received wide attention. Though open nailing has been widely described, closed nailing finds less mention. This paper therefore aims to study the outcome of closed titanium elastic nailing for displaced mid-clavicular fractures. Material and Methods: This was a prospective study of 34 patients with displaced middle third clavicle fracture who underwent closed intramedullary nailing with titanium elastic nail at a tertiary care centre. The operative time, length of incision, time for radiological union, pain and functional outcome after union were noted. Results: The mean operative time was 34.33 mins. The mean time of discharge was 2.25 days. The average time of radiological union was 10.23 weeks. All the patients achieved full, painless range of motion of the ipsilateral shoulder. The average Constant-Murley score at 12 months was 94.28 indicating excellent result. Conclusion: Closed titanium elastic nailing offers a safe and minimally invasive method of fixation for fractures of middle-third clavicle with excellent functional outcome.
\end{abstract}

\section{Keywords}

Clavicle, Fracture, Closed, Titanium Elastic Nailing

\section{Introduction}

Clavicle fracture is one of the common fractures encountered in orthopaedic practice. Though conservative treatment is the most commonly employed modality of treatment in fractures of the middle third, certain situations warrant surgery. Open reduction with plate fixation is most popular modality but known to be associated with hardware complications [1]. Less invasive option is intramedullary nailing with elastic nails [2]-[4]. Open

"Corresponding author. 
reduction with retrograde or antegrade nailing has been well described in the literature with good results [5]. We describe here our experience with outcome of closed nailing of fractures of middle third clavicle.

\section{Materials and Methods}

This study was approved by the local ethics committee and informed consent was obtained from all the patients prior to the commencement of the study. This was a prospective study of 34 clavicular fractures treated by closed titanium elastic nail (TEN). Between the period of April 2008 to Dec. 2012, 86 patients with simple mid-shaft clavicle fractures (OTA classification: 15 B1) presented in the casualty [6] out of which 41 patients were treated conservatively, 11 patients with plating and 34 patients were treated with closed elastic titanium nail. All patients with widely displaced fracture fragments and those who refused to conservative treatment were offered operative treatment. Inclusion criteria for TEN were closed or grade I compound mid-shaft clavicle fracture and non-comminuted fractures. All the patients treated with TEN but had associated injuries in the ipsilateral upper limb were excluded from the study. Also, any grossly comminuted fractures, fracture of the medial or lateral end, grade II or more compound injuries or pathological fractures were excluded from the study. All patients reported history of significant trauma ranging from road traffic accident to fall from significant height. The patients included in the study were explained about the procedure and informed consent was obtained. The width of the medullary canal of the clavicle was assessed on the true size AP view at middle third and at one $\mathrm{cm}$. from the either ends of the clavicle. This was to determine the size of the nail to be inserted. As a rule, nail of size $0.5 \mathrm{~mm}$ less compared to the canal diameter was selected for insertion.

\section{Surgical Technique}

Patient was placed supine. A one $\mathrm{cm}$ transverse incision was taken about two $\mathrm{cm}$ lateral to the sterno-clavicular joint. A drill hole was made into the anterior cortex using a $2.7 \mathrm{~mm}$ drill bit and the medullary canal was entered using awl. A preselected size of TEN was advanced along the medullary canal unto the fracture site under image intensifier control. The fracture was reduced by closed method and the nail advanced across the fracture site into the lateral fragment. Continuous visualization under image intensifier using antero-posterior and oblique views aided advancement of the nail. The bend tip of the nail was rotated to negotiate the entry into the lateral fragment. The nail was advanced only when the surgeon was absolutely sure that it has engaged the lateral fragment. The medial end of the nail was bent and buried in the soft tissue to facilitate easy removal at a later date (Figure 1, Figure 2). All patients were discharged on the next day after the operation. Sutures were removed after two weeks.

The operated arm was supported in an arm-sling support for four weeks. Intermittent pendulum movement was started after two weeks and range of shoulder movement was started after six weeks.

All patients were followed up after every two weeks. At every visit they were assessed for pain using VAS score. Similarly functional assessment was made using Constant-Murley score for shoulder at 12 months. The

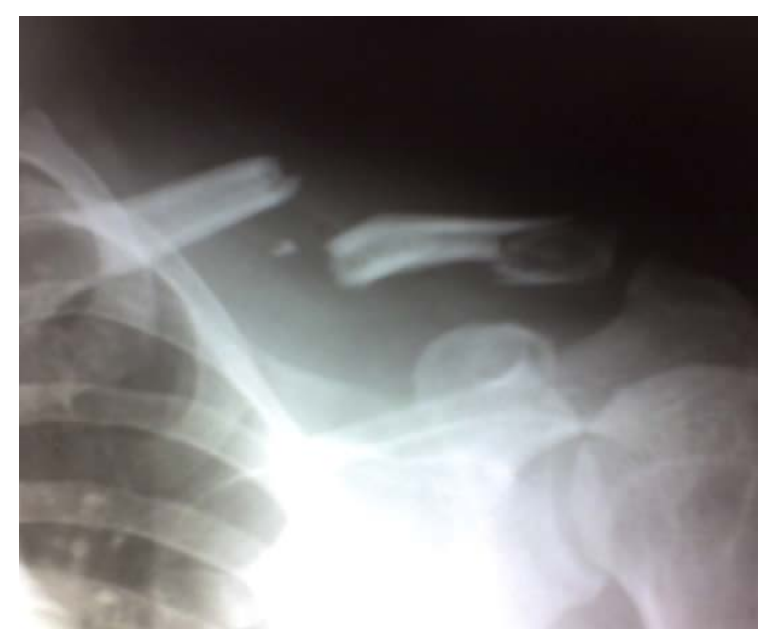

Figure 1. Fracture middle third of clavicle. 


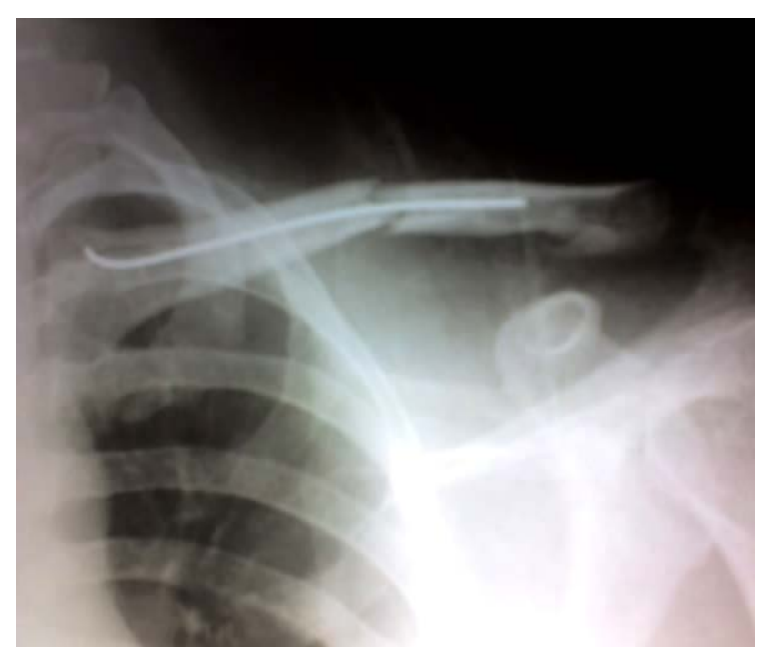

Figure 2. TEN in situ.

radiographs were taken at monthly interval to assess status of union. Patients were also assessed for any complications like infection, hardware related problems etc.

The statistical analysis was carried out using SPSS 16.0 and MS Excel 2003. Statistical analyses tested the null hypotheses of no differences in patients treated at 95\% significance level $(P<0.05)$.

\section{Results}

The demographic data is presented in Table 1 . The mean age of the patients was 38.6 years. Of the total 34 patients 26 were male and 8 were female patients. The mean operative time was $34.3 \mathrm{~min}$. The average length of the incision was $1.62 \mathrm{cms}$. The average time of discharge was 1.65 days. The minimum length of follow up was 12 months, with average of 13.2 months and range of 12 to 15 months. The mean time for radiological union was 10.23 weeks. The mean Constant-Murley score was 94.28 at 12 months indicating excellent outcome. The average VAS score at discharge was 3.63 which decreased to 0.43 at union when active mobilization had commenced (Table 2). There were no major intraoperative or postoperative complications noted. One patient complained of prominent hardware at the medial end of the clavicle. The nail was removed under short general anaesthesia after 8 months postoperatively. Also, one patient had superficial infection at the entry site of the nail which healed with oral antibiotics. All patients returned to their pre-injury activity at the end of 6 months.

\section{Discussion}

Most of the middle third clavicle fractures are treated conservatively with operative treatment reserved for compound or impending compound fractures, polytrauma patients or non-unions [6]. Though the union rate is satisfactory, wearing brace for weeks together is cumbersome and at times lead to non-compliance of the patients. Most common operative option sought for fixation of clavicular fractures is plate fixation [1] [7]. Though quality of reduction and fixation is good it involves an ugly scar and more chances of hardware problems. A very attractive solution for middle third fractures is intramedullary nail fixation. This modality fulfills most of the desired goals of clavicle fixation. It restores the length and alignment of the bone in the least invasive fashion. The operative time is reduced, intraoperative bleeding is reduced, postoperative pain is less and rehabilitation is faster [3] [8]-[10].

Various techniques of intramedullary nail fixation have been reported in literature. Some advocate insertion of the nail from the fracture site while some advocate medial entry [2] [3] [5]. Most studies advocate open reduction of the fragments [3] [5]. This is probably to avoid any damage to important neurovascular structures and the pleura. Though we do not deny the fact of a possible injury to important structures we believe it can be avoided by meticulous technique. In this paper TEN with a T-handle was used to advance the nail. The TEN has a blunt and curved advancing end which prevents inadvertent injury to vital structures. We also advocate gentle controlled tap of the nail as it passes across the fracture site than vigorous longitudinal uncontrolled push. Similarly 
Table 1. Demographic data.

\begin{tabular}{cc}
\hline Variable & No./Mean \pm SD (Range) \\
\hline Sex & $26(76.47 \%)$ \\
Male & $08(23.53 \%)$ \\
Female & $38.6 \pm 5.3(22-45)$ \\
\hline Age (years) & \\
\hline Table 2. Results. & Mean \pm Std. Dev. (Range) \\
\hline Variable & $34.33 \pm 10.52(20-68)$ \\
\hline Operative time (min.) & $1.62 \pm 0.25(0.8-2.1)$ \\
Length of incision (cms.) & $1.65 \pm 0.42(1-3)$ \\
Time of discharge (days) & $10.23 \pm 2.65(08-16)$ \\
Radiological union (weeks) & $94.28 \pm 3.75(89-98)$ \\
Constant-Murley score at 12 months & $3.63 \pm 0.74(1-5)$ \\
VAS at discharge & $0.43 \pm 0.22(0-2)$ \\
\hline VAS at union &
\end{tabular}

continuous image intensifier guidance is taken in anteroposterior and oblique views and surgeon does not advance the nail unless he is absolutely sure of its engagement into the lateral fragment. By this technique we did not encounter any intraoperative or post-operative complications.

We compared our technique with open nailing [11]-[14]. The results are comparable in terms of operative time, shoulder scores and time to union. Similarly, there are very few studies in the English literature describing closed nailing. Chen et al. described the technique closed reduction and nail fixation in middle third fractures of clavicle with good results [15]. Our results are comparable to this study. Yih-Shuinn-Lee et al. in their paper compared plate fixation with Knowles pin fixation and noted operative time of $27 \mathrm{~min}$, shoulder score of 95 and union time of 6 months with pin fixation which is comparable to our study [2]. Similarly Jamal E.H. Assobhi in his paper comparing pin fixation with plate fixation noted operative time of $44 \mathrm{~min}$ and hospital stay of 1.4 days with pin fixation which is similar to the findings of this study [3].

There are certain limitations of the study. This is not a comparative study but we believe that it has been proved in the literature that fixation by nail yields superior results when compared to plate fixation in terms of cosmesis and hardware complications. The main aim of this paper was to present the results of technique of closed reduction and nail fixation. We also agree that the sample size is small. The follow up may be relatively short especially to assess the hardware problems. But we believe that hardware problems if were to occur after union can be easily tackled by removal of nail which is as less invasive as primary surgery.

Lastly we would also like add a word of caution. Though no complications were encountered in this study there always remains a risk of injury to vital mediastinal structures. One should have a very low threshold to open the fracture for reduction in case closed reduction is difficult.

\section{Conclusion}

Closed Titanium elastic nailing is a good alternative modality of fixation in simple, non-comminuted fractures of middle third of clavicle. It is less invasive surgery and yields comparable functional outcomes.

\section{Conflict of Interest}

The authors have no conflict of interest to declare.

\section{References}

[1] Wijdicks, F.J., Van der Meijden, O.A., Millett, P.J., et al. (2012) Systematic Review of the Complications of Plate Fix- 
ation of Clavicle Fractures. Archives of Orthopaedic and Trauma Surgery, 132, 617-625. http://dx.doi.org/10.1007/s00402-011-1456-5

[2] Lee, Y.-S., Huang, H.-L., Lo, T.-Y., et al. (2008) Surgical Treatment of Midclavicular Fractures: A Prospective Comparison of Knowles Pinning and Plate Fixation. International Orthopaedics (SICOT), 32, 541-545. http://dx.doi.org/10.1007/s00264-007-0352-7

[3] Assobhi, J.E.H. (2011) Reconstruction Plate versus Minimal Invasive Retrograde Titanium Elastic Nail Fixation for Displaced Midclavicular Fractures. Journal of Orthopaedics and Traumatology, 12, 185-192. http://dx.doi.org/10.1007/s10195-011-0158-7

[4] Braun, K.F., Siebenlist, S., Sandmann, G.H., Martetschläger, F., Kraus, T., Schrödl, C., Kirchhoff, C. and Neumaier, M. (2014) Functional Results Following Titanium Elastic-Stable Intramedullary Nailing (ESIN) of Mid-Shaft Clavicle Fractures. Acta Chirurgiae orthopaedicae et Traumatologiae, 81, 118-121.

[5] Chen, Y.-F., Zeng, B.-F., Chen, Y.-J., et al. (2010) Clinical Outcomes of Midclavicular Fractures Treated with Titanium Elastic Nails. Canadian Journal of Surgery, 53.

[6] Marsh, J.L., Slongo, T.F., Agel, J., et al. (2007) Fracture and Dislocation Classification Compendium-2007: Orthopaedic Trauma Association Classification, Database and Outcomes Committee. Journal of Orthopaedics and Traumatology, 21, S1-S133. http://dx.doi.org/10.1097/00005131-200711101-00001

[7] Smekal, V., Oberladstaetter, J., Struve, P., et al. (2009) Shaft Fractures of the Clavicle: Current Concepts. Archives of Orthopaedic and Trauma Surgery, 129, 807-815. http://dx.doi.org/10.1007/s00402-008-0775-7

[8] Kleweno, C.P., Jawa, A., Wells, J.H., et al. (2011) Midshaft Clavicular Fractures: Comparison of Intramedullary Pin and Plate Fixation. Journal of Shoulder and Elbow Surgery, 20, 1114-1117. http://dx.doi.org/10.1016/j.jse.2011.03.022

[9] Chen, Y.F., Wei, H.F., Zhang, C., et al. (2012) Retrospective Comparison of Titanium Elastic Nail (TEN) and Reconstruction Plate Repair of Displaced Midshaft Clavicular Fractures. Journal of Shoulder and Elbow Surgery, 21, 495501. http://dx.doi.org/10.1016/j.jse.2011.03.007

[10] Duan, X., Zhong, G., Cen, S., et al. (2011) Plating versus Intramedullary Pin or Conservative Treatment for Midshaft Fracture of Clavicle: A Meta-Analysis of Randomized Controlled Trials. Journal of Shoulder and Elbow Surgery, 20, 1008-1015. http://dx.doi.org/10.1016/j.jse.2011.01.018

[11] Liu, H.H., Chang, C.H., Chia, W.T., et al. (2010) Comparison of Plates versus Intramedullary Nails for Fixation of Displaced Midshaft Clavicular Fractures. Journal of Trauma-Injury Infection \& Critical Care, 69, E82-E87. http://dx.doi.org/10.1097/TA.0b013e3181e03d81

[12] Smekal, V., Irenberger, A., Attal, R.E., et al. (2011) Elastic Stable Intramedullary Nailing Is Best for Mid-Shaft Clavicular Fractures without Comminution: Results in 60 Patients. Injury, 42, 324-349. http://dx.doi.org/10.1016/j.injury.2010.02.033

[13] Liu, P.C., Chien, S.H., Chen, J.C., et al. (2010) Minimally Invasive Fixation of Displaced Midclavicular Fractures with Titanium Elastic Nails. Journal of Orthopaedic Trauma, 24, 217-223. http://dx.doi.org/10.1097/BOT.0b013e3181b8ba33

[14] Kraus, T.M., Martetschläger, F., Schrödl, C., et al. (2011) Elastic Stable Intramedullary Nailing of Clavicular Midshaft Fractures: Comparison of Open vs Closed Fracture Reduction. Article in German, Unfallchirurg.

[15] Chen, P.Y., Lin, C.C., Wang, C.C., et al. (2004) Closed Reduction with Intramedullary Fixation for Midclavicular Fractures. Orthopedics, 27, 459-462. 